\title{
Linfoma de colon como causa de fiebre de origen desconocido
}

\author{
S. CASALLO BLANCO, L. DE MATÍAS SALCES, F. MARCOS SÁNCHEZ, \\ M. J. MARTÍN BARRANCO, E. NÚÑEZ CUERDA, F. SOLANO RAMOS ${ }^{1}$ \\ Servicios de Medicina Interna $y^{\prime}$ Hematología. Hospital Nuestra Señora del Prado. \\ Talavera de la Reina. Toledo
}

\author{
COLON LYMPHOMA AS A CAUSE OF FEVER OF UNKNOWN \\ ORIGIN
}

\section{RESUMEN}

Presentamos el caso de un varón de 49 años que presentó un cuadro de fiebre de dos meses de evolución, acompañado de nauseas, vómitos y perdida de 10 kilogramos de peso. Con el diagnostico de fiebre de origen desconocido ingresó. En la TAC abdominal se objetivó un extenso engrosamiento de la pared de colon transverso y ángulo hepático, sugestivo de neoplasia de colon y una gran lesión sólida en lóbulo hepático izquierdo. Se realizó una colonoscopia observándose una neoplasia circunferencial, tomándose biopsias. La anatomía patológica fue informada de linfoma de células grandes difuso tipo B.

El linfoma primario de colon es un tumor muy poco frecuente del tracto gastrointestinal, no superando el $1 \%$ en las series consultadas. Basándonos en este caso se hizo una revisión de los artículos más recientes sobre linfoma gastrointestinal.

PALABRAS CLAVE: Linfoma primario de colon. Linfoma de células B. Fiebre de origen desconocido.

\begin{abstract}
We present a case of a 49 year old man who presented with a 2 month history of fever, nausea vomiting and weight loss (10 kg). He was admitted to the Hospital with the diagnosis of fever of unknown origin. A $C T$ scan showed a wide thickening of the colonic wall (transverse colon and hepatic flexure) suggesting a colon tumor, and a solid mass in the left liver lobe. A colonoscopy was performed showing a circumferential neoplasm and biopsies were taken. The histopathology was informed as a diffuse large B cell lymphoma.

Primary colon lymphoma is a rare gastrointestinal tumor that represents less than $1 \%$ of the gastrointestinal lymphomas.

Based on this case, we reviewed the most recent articles about gastrointestinal lymphomas.
\end{abstract}

KEY WORDS: Colon lymphoma. B cell lymphoma. Fever of unknown origin.

Casallo Blanco S, de Matías Salces L, Marcos Sánchez, F, Martín Barranco MJ, Núñez Cuerda E, Solano Ramos F. Linfoma de colon como causa de fiebre de origen desconocido. An Med Interna (Madrid) 2006; 23: 379-381.

\section{INTRODUCCIÓN}

Fiebre de origen desconocido (FOD) se define por Petersdorf y Beeson (1) como la temperatura igual o superior a $38,3{ }^{\circ} \mathrm{C}$, tomada en varias ocasiones, de más de tres semanas de evolución y que permanece sin diagnosticar después de una semana de estudio hospitalario. Definiciones posteriores han intentado adaptarse al cambio de espectro de esta enfermedad a lo largo de estos 40 años, ante la posibilidad de que la evaluación del paciente pueda realizarse de forma ambulatoria y debido a la posible presentación de esta entidad en situaciones especiales que incluyen fiebre nosocomial, asociado a inmunosupresión, neutropenia e infección por VIH, incluyendo la fiebre episódica recurrente descrita recientemente (2). Por lo que actualmente se define FOD como la fiebre igual o supe- rior a $38{ }^{\circ} \mathrm{C}$ determinada en varias ocasiones, de más de tres semanas de evolución, sin diagnóstico después de un estudio de tres días de hospitalización o tres visitas extrahospitalarias.

La prevalencia de la FOD varía en función del área geográfica, tipo de población estudiada, recursos sanitarios, huésped y factores microbiológicos. Los avances técnicos y científicos han facilitado el diagnóstico diferencial y etiológico. El porcentaje de etiología no diagnosticada ha pasado de un $75 \%$ en los años 30 a alrededor de un $10 \%$ en la época actual, ya que se ha beneficiado del desarrollo de la inmunología.

Las causas de mayor prevalencia incluyen las infecciones, neoplasias y enfermedades sistémicas de patogenia autoinmune. En nuestro medio, las infecciones son la causa más frecuente de FOD (41,2\%), seguida por las neoplasias $(19,2 \%)$ y conectivopatías-vasculitis $(13,7 \%)$. La entidad infecciosa más

Trabajo aceptado: 15 de febrero de 2006 
frecuente es la tuberculosis, seguida de la brucelosis y abscesos. La mitad de las neoplasias responsables de FOD son linfomas. El lupus eritematoso sistémico, la panarteritis nodosa y la arteritis de células gigantes son responsables de la FOD en el 28,8, 21,6 y $20 \%$, respectivamente, de las conectivopatíasvasculitis.

\section{CASO APORTADO}

Varón de 49 años que había consultado en varias ocasiones a urgencias y a su médico de familia por fiebre superior a $38^{\circ}$ de 2 meses de evolución, acompañada de nauseas, vómitos y pérdida de unos 10 kilogramos de peso. El paciente era exfumador, estaba diagnosticado de hepatopatía criptogenética, taquicardia por vía aberrante en la que se había realizado ablación 10 años atrás, episodio de angor con coronariografía normal, síndrome ansioso-depresivo e intervenido de ulcus duodenal y apendicitis. No había realizado viajes recientemente y no refería prácticas sexuales de riesgo.

En el examen clínico se objetivaba una temperatura de $39,7^{\circ} \mathrm{C}$, se palpaba hepatomegalia a unos 3-4 centímetros del reborde costal, siendo el resto de la exploración normal. En cuanto a las pruebas complementarias destacaban $15.900 / \mathrm{mm}^{3}$ leucocitos con desviación izquierda, hemoglobina de $10.5 \mathrm{~g} / \mathrm{dl}$ y una VSG de $101 \mathrm{~mm}$. En la bioquímica existía una alteración de los parámetros hepáticos: GOT 101 U/l, GPT 128 U/l, FA 208 U/l, GGT 172 U/l, LDH 1366 UI/l. La PCR se encontraba asimismo elevada.

Se realizó un sistemático de orina que fue normal, Mantoux negativo. Serologías de Brucella, Leishmania, C. Burnetti, lúes, Salmonella, virus de la hepatitis A, B y C y VIH negativos. También se realizaron serologías de citomegalovirus, virus de Epstein-Barr y toxoplasma que fueron $\operatorname{IgG}+$ y $\operatorname{IgM}$ negativos.

Hemocultivos durante el estudio ambulatorio y hospitalizado fueron negativos. Se realizó una radiografía de tórax que fue normal y una ecografía abdominal donde se observó hígado, vía biliar, vesícula, porción visible de retroperitoneo superior y porta sin hallazgos ecográficos significativos. Posteriormente se efectúo una TAC abdominal (Fig. 1) en la que se apreció un extenso engrosamiento mamelonado de la pared de colon transverso y del ángulo hepático de aproximadamente $12 \mathrm{~cm}$ de longitud, sugestivo de neoplasia de colon; gran lesión sólida con captación heterogénea de contraste en lóbulo hepático izquierdo segmento IV, sugestiva de metástasis. Ante estos

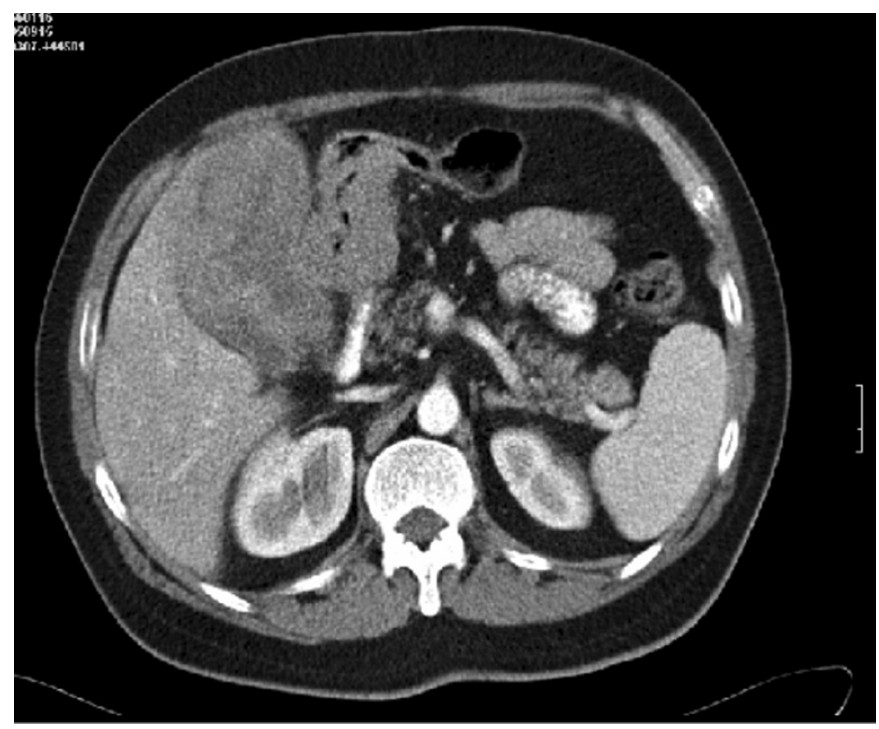

Fig. 1. Extenso engrosamiento de la pared del colon transverso y gran lesión sólida en lóbulo hepático izquierdo (segmento IV). hallazgos se realizó un enema opaco donde se observó un defecto de repleción en "corazón de manzana" a nivel de la unión de colon transverso con ángulo hepático en un tramo aproximadamente de 12 centímetros. Además se realizó una colonoscopia en la que se apreció una neoplasia circunferencial a $110 \mathrm{~cm}$ del ano que impedía el paso del endoscopio, tomándose biopsias. La anatomía patológica fue informada como tejido de granulación y tejido conectivo en los que se apreciaban densos infiltrados linfocitarios con predominio CD20+ que con frecuencia expresaban tinción nuclear bcl-6. Los cambios morfológicos sugerían un linfoma tipo B aunque no era concluyente por lo que se realizó PAAF hepática confirmando el diagnóstico de linfoma de células grandes difuso tipo B.

Posteriormente se paciente fue remitido a hematología, donde se inició tratamiento de quimioterapia siguiendo el esquema $\mathrm{CHOP}$ (ciclofosfamida, doxorrubicina, vincristina y prednisona) y de momento no tenemos datos sobre la eventual respuesta tumoral.

\section{DISCUSIÓN}

Los linfomas gastrointestinales primarios representan una entidad clinicopatológica diferente a los linfomas ganglionares. Son los más frecuentes entre los linfomas extraganglionares constituyendo entre el $1-4 \%$ de todos los tumores malignos del tubo digestivo. El $20 \%$ de las neoplasias malignas del intestino delgado son linfomas no Hodgkin. El 7\% de las neoplasias malignas gástricas corresponden a linfomas, sin embargo en colon y en recto no superan el $1 \%$ (4).

Dado que a veces los linfomas ganglionares invaden el tracto digestivo se han establecido unos criterios diagnósticos estrictos, definidos por Dawson: a) ausencia de linfadenopatías periféricas; b) ausencia de linfadenopatías mediatínicas en la radiografía de tórax; c) frotis de sangre periférica normal; d) al realizar la laparotomía exista compromiso únicamente del esófago, estómago y el intestino o de ganglios regionales; y e) ausencia de compromiso hepático y esplénico; excepto por la diseminación directa de la enfermedad a partir de un foco adyacente.

Los linfomas del tracto gastrointestinal derivan del sistema linfoide de la mucosa. Suelen ser predominantemente linfoma no Hodgkin tipo B y dentro de la clasificación histológica el histiocítico difuso (5). Pero discernir estas características implica realizar estudios histológicos e inmunohistoquímicos.

Se asocia a enfermedades como esprue celiaco, colitis ulcerosa, VIH, herpes virus y fármacos como la fdifenilhidantoína y corticoides a altas dosis y de modo prolongado.

Los signos y síntomas más destacables dependen de la ubicación de la lesión, así en el colon se caracterizará por un cuadro de dolor abdominal, perdida de peso, estreñimiento y hemorragia gastrointestinal.

En la analítica puede existir anemia y el resto suele ser normal.

Los estudios por imagen son útiles para determinar el lugar de la lesión y el grado de compromiso, pero los resultados no serán obviamente concluyentes para el diagnóstico.

La endoscopia constituye el procedimiento de elección en el diagnóstico de los linfomas primarios de estómago y colon, ya que permite la toma de biopsias para el estudio histológico.

Las modalidades de tratamiento comprenden cirugía, quimioterapia y/o radioterapia.

La asociación de los linfomas MALT y Helicobacter pylo$r i$ ha sido demostrada, ya que tras la erradicación de esta bac- 
teria se ha objetivado la regresión del linfoma. En un estudio tras conseguir la erradicación de $H$. pylori, en el $50-80 \%$ de los pacientes seleccionados ocurrió la regresión del linfoma (6). También se ha apreciado regresión del linfoma tipo MALT en intestino delgado y recto, sugiriendo el papel etiológico de la bacteria en estos lugares.

Una observación reciente sugiere que la expresión nuclear de bcl 10 y/o la $\mathrm{t}(11 ; 18)$ identifica a pacientes con linfomas que no se beneficiarían de la terapia erradicadora (7).

Los pacientes con una afectación intestinal extensa o un

\section{Bibliografía}

1. Petersdorf RG, Beeson PB. Fever of unexplained origin: Report on 100 cases. Medicine (Baltimore) 1961; 40:1-30.

2. Durack DT, Street AC. Fever or unknown origin reexamined and redefined. En: Remington JS, Swartz MN, editors. Current Clinical Topics in Infectious Diseases. Boston: Blackwell; 1991, 35-51.

3. Barbado FJ, Vázquez JJ, Peña JM, Arnalich F, Ortiz-Vázquez J. Pyrexia of unknown origin: changing spectrum of diseases in two consecutive series. Postgrad Med J 1992; 68: 884-7.

4. Koch, P, del Valle, F, Berdel, WE. Primary gastrointestinal non-hodgkin's: anatomic and histologic distribution, clinical features, and survival data of 371 patients registered in the german multicenter study git nhl 01/92. J Clin Oncol 2001; 19: 3874-83.

5. Montserrat E, Díaz J. Enfermedades ganglionares. En: Farreras Roz- estadio más avanzado de la enfermedad se les deben ofrecer otro tipo de tratamiento. Afortunadamente, los pacientes que no responden a terapia erradicadora, así como en los linfomas de alto grado todavía tiene alto índice de curación, así tras recibir tratamiento de quimioterapia y/o radioterapia, la supervivencia a los cinco años alcanza al 80-90\%. La quimioterapia con multiagentes como el CHOP está reservada a pacientes con fallo del tratamiento erradicador, recidiva tras terapias menos agresivas o enfermedad avanzada (estadios IE o estadios III o IV) (8). man. Medicina Interna. 13 ${ }^{\mathrm{a}}$ edición Madrid. Harcourt Brace. 1997: 1729-1752.

6. Bertoni, F, Conconi, A, Capella, C. Molecular follow-up in gastric mucosa-associated lymphoid tissue lymphomas: early analysis of the LYO3 coperative trial. Blood 2002; 99: 2541-4.

7. Yeh, Kh, Kuo, SH, Chen, LT. Nuclear expression of BCL10 or nuclear factor kappa B helps predict Helicobacter pylori-independent status of low-grade gastric mucosa-associated lymphoid tissue lymphomas with or without $\mathrm{t}(11 ; 18)(\mathrm{q} 21 ; \mathrm{q} 21)$. Blood 2005; 106: 1037-41. Epub 2005 Apr 21.

8. Hitchcock, S, NG, AK, Fisher, DC. Treatment outcome of mucosa-associated lymphoid tissue/marginal zone non-Hodgkin's lymphoma. Int J Radiact Oncol Biol Phys 2002; 52: 1058-66. 